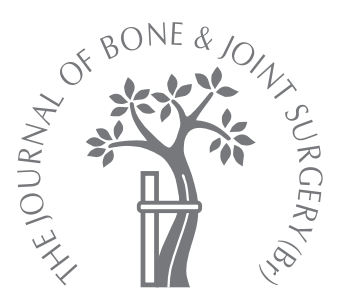

M. Pospischill,

K. Knahr

From the

Orthopaedic

Hospital, Vienna,

Austria

\title{
Cementless total hip arthroplasty using a threaded cup and a rectangular tapered stem
}

\author{
FOLLOW-UP FOR TEN TO 17 YEARS
}

We carried out a clinical and radiological review of 103 cementless primary hip arthroplasties with a tapered rectangular grit-blasted titanium press-fit femoral component and a threaded conical titanium acetabular component at a mean follow-up of 14.4 years (10.2 to 17.1).

The mean Harris hip score at the last follow-up was 89.2 (32 to 100). No early loosening and no fracture of the implant were found. One patient needed revision surgery because of a late deep infection. In 11 hips (10.7\%), the reason for revision was progressive wear of the polyethylene liner. Exchange of the acetabular component because of aseptic loosening without detectable liner wear was carried out in three hips (2.9\%).

After 15 years the survivorship with aseptic loosening as the definition for failure was $\mathbf{9 5 . 6} \%$ for the acetabular component and $\mathbf{1 0 0} \%$ for the femoral component.

For three decades, orthopaedic surgeons have debated the best method for fixation of the implant in total hip arthroplasty (THA). During this period many implants have undergone changes in design and/or material. Few longterm clinical and radiological studies of unchanged implants still in current usage are available. This is especially true for cementless implants. ${ }^{1-3}$

The Alloclassic hip (Alloclassic SL, Zimmer/ Centerpulse, Winterthur, Switzerland) was introduced in $1979,{ }^{4}$ and after some early modifications, no further alterations have been undertaken since 1987. The anchoring principle has been described by various authors. ${ }^{5,6}$ Primary fixation of the cementless tapered titanium femoral component is achieved by diaphyseal press-fit and secondary stability by bone ongrowth onto the grit-blasted surface. The threaded conical acetabular component obtains initial fixation by conical threads, gaining longterm stability by bone ongrowth on its rough titanium surface. Although more than 250000 implantations have been performed worldwide to date, there have been only a few long-term studies. ${ }^{7-10}$ Our aim, therefore, was to present the clinical and radiological findings including a survival analysis of a consecutive series followed for a mean period of 14.4 years (10.2 to 17.1 ).

\section{Patients and Methods}

Design of the implant. The femoral component is a tapered straight stem, wrought of a Prota- sul titanium alloy TiA1Nb. In its horizontal section, the shape is rectangular, allowing a secure diaphyseal press-fit in the frontal plane of the femoral canal. This provides excellent rotational stability and increases primary mechanical fixation. To achieve permanent secondary stability by osseous fixation, the stem is grit-blasted over its entire surface with corundum particles to produce a mean roughness of 4 to $6 \mu \mathrm{m}$.

The conical self-cutting cementless threaded acetabular component (Alloclassic; CSF, Zimmer/Centerpulse) is forged of pure titanium. The conical threads cut sharply into the acetabular bone gaining a stable primary fixation to allow osseous ongrowth onto the rough titanium surface.

The prosthesis was used in combination with an alumina-ceramic head $32 \mathrm{~mm}$ in diameter, fixed on a 14/16 mm taper, and with an ultrahigh-molecular-weight polyethyelene (UHMWPE) inlay, sterilised under inert gas atmosphere.

Patients. From a total number of 152 primary THAs (148 patients), 103 hips (99 patients) were available for clinical and radiological evaluation with a minimum follow-up of ten years. Four patients had had bilateral procedures.

Thirty-one patients died before reaching the minimum clinical and radiological follow-up period of ten years for reasons unrelated to the hip surgery. However, they had a mean clinical and radiological follow-up of 6.9 years $(0.3$ to 


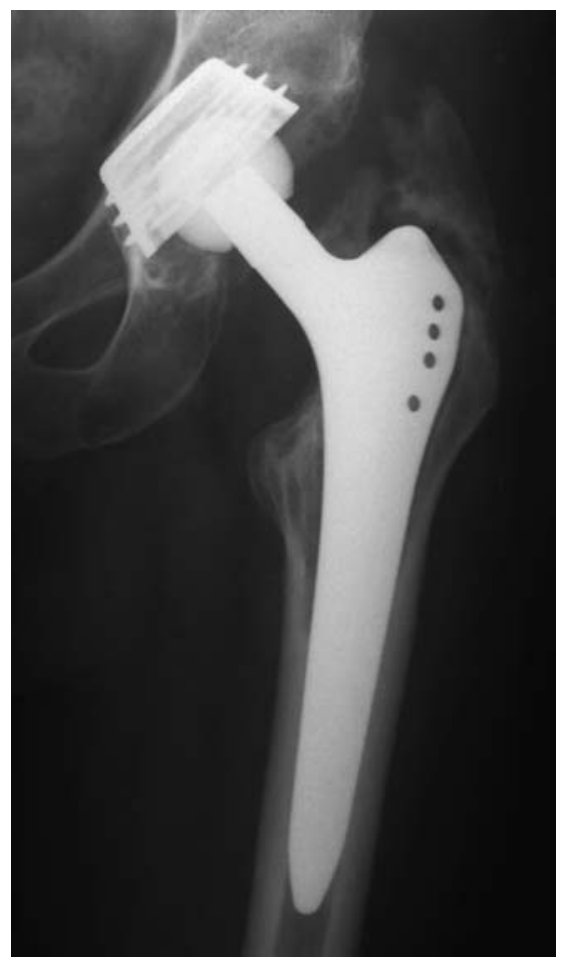

Fig. 1a

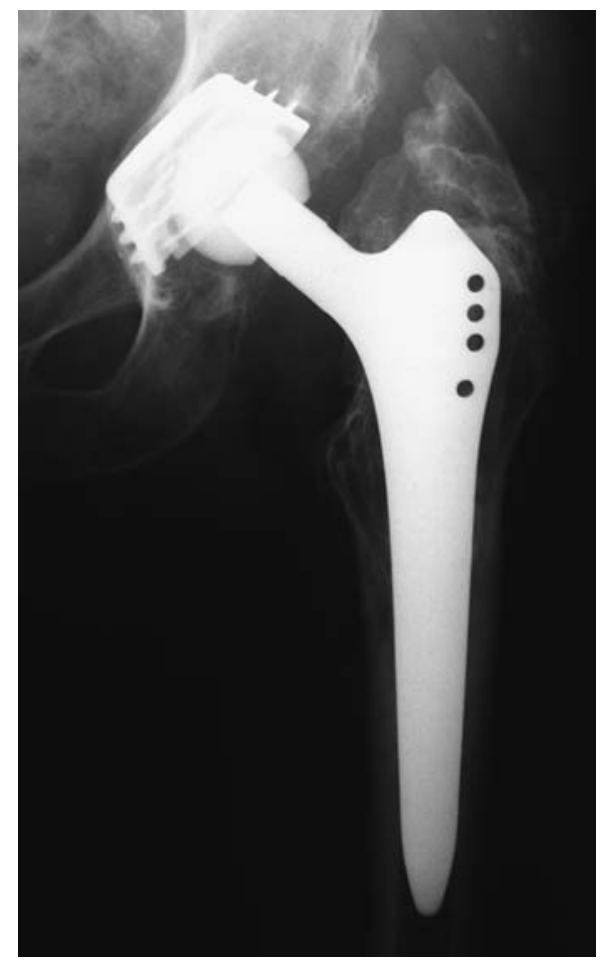

Fig. 1b

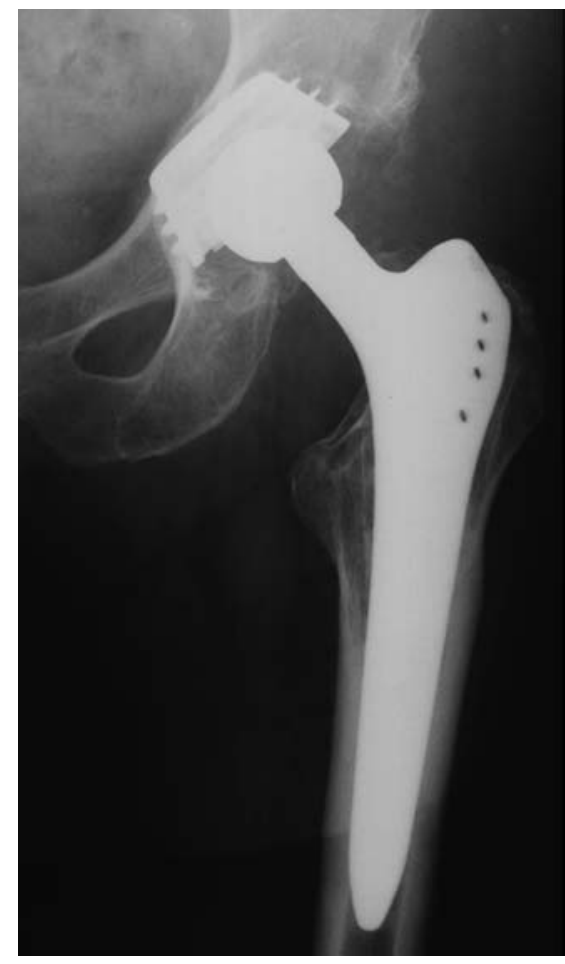

Fig. 1c

Radiographs showing an Alloclassic THA system a) three months after surgery, b) before exchange of the inlay and head because of polyethylene wear 15.8 years after the initial surgery and c) after revision surgery and implantation of a polyethylene-ceramic bearing.

9.3). In three the only follow-up was at three months after operation. It was not possible to obtain any further information about these patients. In 19 the exact date of death was unknown. These patients were censored in the survival analysis at their last visit. Nine patients died with the prostheses still in place. They were censored at the date of death.

Nine patients were unable or unwilling to attend for review because of distance or immobility. They underwent a telephone interview and were censored in the survival analysis by the date of this contact. One patient was revised at another clinic because of a late deep infection at 7.4 years. Eight patients were untraceable after a mean followup of six years.

The mean age of the patients at the initial operation was 59.2 years (28.4 to 84.0$)$. One hundred and six prostheses were implanted in women and 46 in men.

In 86 patients $(58.1 \%)$, the indication for hip surgery was idiopathic osteoarthritis, in $26(17.6 \%)$ avascular necrosis of the femoral head, in $23(15.5 \%)$ developmental dysplasia of the hip, in seven $(4.7 \%)$ post-traumatic osteoarthritis and in six (4.1\%) rheumatoid arthritis.

Evaluation. The clinical results were evaluated at a standardised follow-up visit at least ten years after implantation to assess the Harris hip score. ${ }^{11}$ In the event of revision, data at the last follow-up before re-operation were included. Additionally, all patients were requested to complete SF-36 and WOMAC questionnaires. ${ }^{12,13}$
Radiographs were analysed according to the method of DeLee and Charnley ${ }^{14}$ for the acetabular component. On the femoral side, the zones described by Gruen, McNeice and Amstutz ${ }^{15}$ were used. A previous report ${ }^{16}$ has shown that the lateral radiographs revealed the same findings as the anteroposterior (AP) views for this implant. Accordingly, we confined our study to the AP films.

Periprosthetic heterotopic ossification was classified according to the criteria of Brooker et al. ${ }^{17}$

Linear polyethylene wear was measured by comparing the distance from the superior margin of the acetabular component to the edge of the femoral head with that from the inferior margin of the acetabular component to the femoral head on the AP radiographs. Linear wear was defined as half the difference between these measurements, which were corrected for magnification by comparing the diameter of the femoral head on each individual radiograph with the known diameter of $32 \mathrm{~mm} .{ }^{18}$ Osteolysis was defined as a radiolucent cystic lesion at the implant-bone interface.

Subsidence of the femoral component was defined by the distance measured between the most medial point of the lesser trochanter and the proximal tip of the stem on the pelvic radiograph. Correction for magnification was based on the femoral head diameter. All measurements were made by a single observer using a caliper.

Statistical analysis. Survivorship analysis was undertaken by calculating life tables ${ }^{19}$ and Kaplan-Meier curves ${ }^{20}$ 


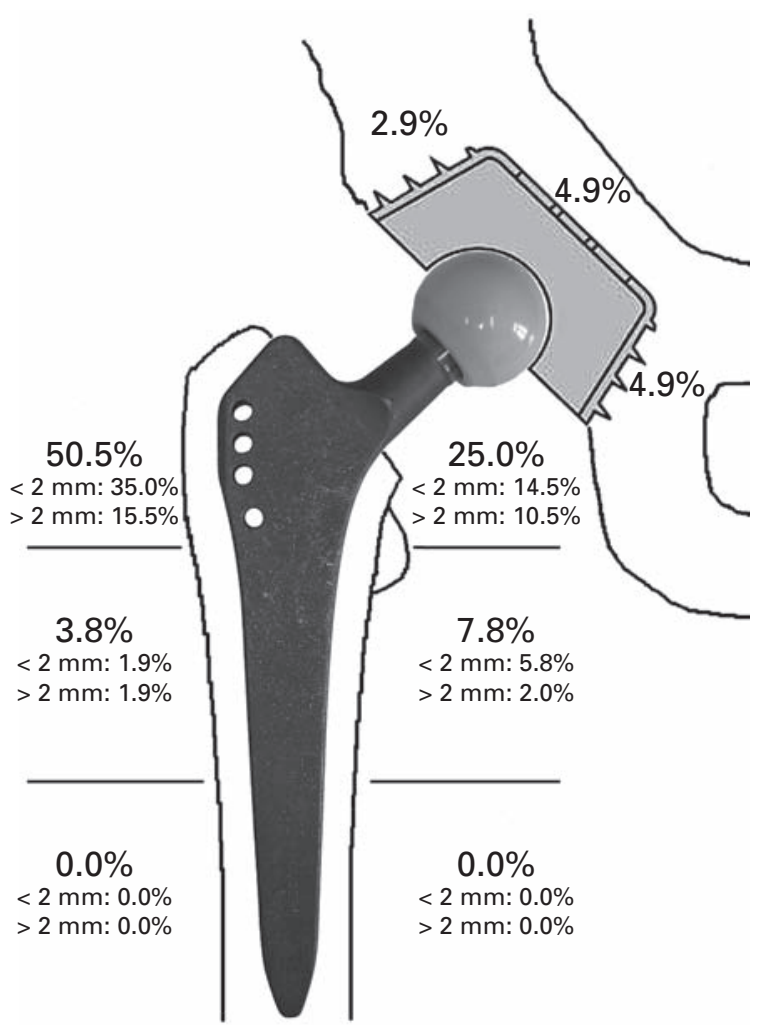

Fig. 2a

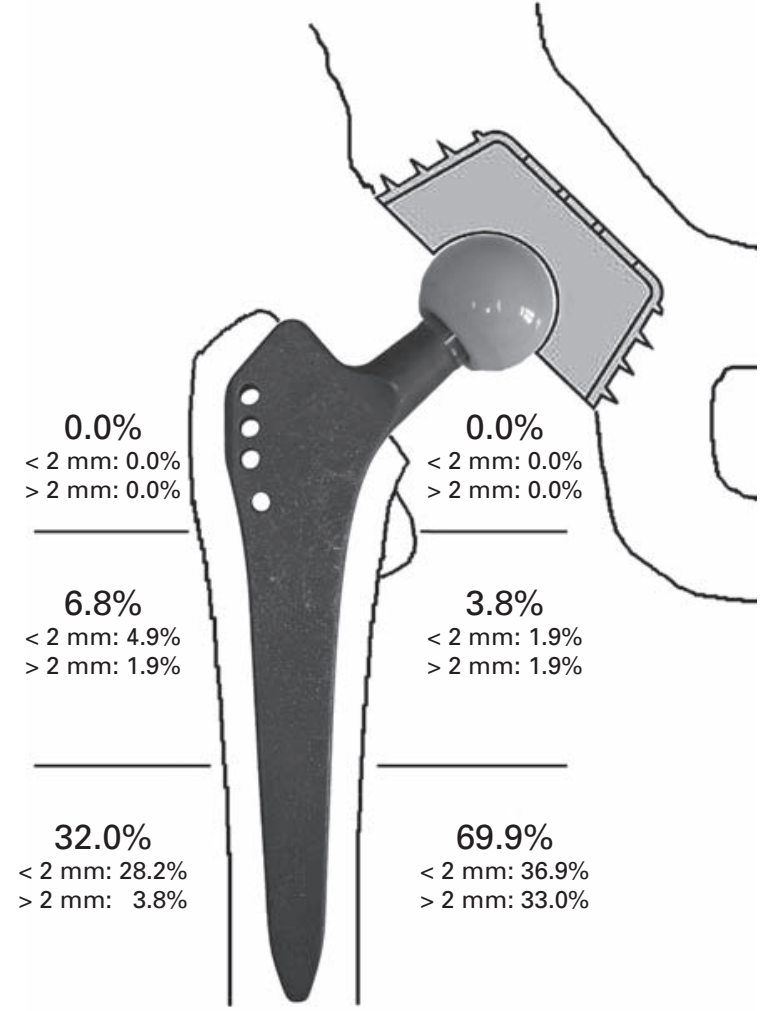

Fig. 2b

Diagrams of the typical bone remodelling process after a mean follow-up period of 14.4 years using a cementless threaded cup and a rectangular tapered stem showing the incidence of a) radiolucent lines and b) cortical hypertrophy.

including a confidence interval (CI) of $95 \%$, as recommended by Murray, Carr and Bulstrode. ${ }^{21}$

\section{Results}

Revisions. Fifteen hips (14.6\%) were revised, 14 of them after the minimum follow-up period of ten years. One patient needed revision surgery because of a late deep infection after 7.4 years. No early loosening and no breakage of the implant occurred in this series. All aseptic revisions were related to the acetabular side (wear or loosening).

In 11 hips $(10.7 \%)$, the reason for revision was progressive UHMWPE wear. Exchange of the polyethylene inlay and the ceramic head alone was performed in eight hips. In two cases the titanium acetabular component, and in one the femoral component were also found to be loose intraoperatively because of polyethylene wear debris; these were revised. All articulating wear partners were changed to a metal-on-metal or UHMWPE-on-ceramic bearing (Fig. 1). Exchange of the acetabular component because of aseptic loosening without signs of increased polyethylene wear was performed in three hips $(2.9 \%)$.

Clinical. The latest mean post-operative Harris hip score was 89.2 (32 to 100). At a mean follow-up of 14.4 years, the clinical ratings were graded as excellent and good in 83
$(80.1 \%)$, fair in eight $(7.7 \%)$ and poor in $12(11.6 \%)$ of all reviewed hips. The mean pain score was 41.6 (10 to 44$)$ and the mean functional score 47.6 (17 to 56).

A maximum pain score of 44 (i.e no pain) was found in $89(86.4 \%)$ of all evaluated hips. For the remainder pain was located in the gluteal region in three $(2.9 \%)$, and in the region of the greater trochanter in $12(11.6 \%)$. Three patients $(2.9 \%)$ had inguinal pain and nine $(8.7 \%)$ reported mild pain in changing weather conditions.

Two patients $(1.9 \%)$ suffered from mild thigh pain. None showed radiological signs of increased polyethylene wear or aseptic loosening.

With respect to the SF-36 and WOMAC questionnaires $78(75.7 \%)$ were returned fully completed and could be evaluated. The mean results of the SF-36 domains were: physical functioning 48.2; role physical 45.4; bodily pain 56.6; general health 54.2; vitality 49.5 ; social functioning 72.8; role emotional 66.2; mental health 66.8. The mean WOMAC scores for pain were 2.8 and 3.9 for stiffness and function.

\section{Radiological findings}

Acetabular component. Of the 103 implanted acetabular components, $100(97.1 \%)$ were considered to be stable based on comprehensive osseointegration after a minimum period of ten years. Three $(2.9 \%)$ showed a continuous 
Table I. Life-table survival analysis of 152 uncemented hip arthroplasties using revision for any reason as an end-point

\begin{tabular}{|c|c|c|c|c|c|c|c|}
\hline $\begin{array}{l}\text { Annual } \\
\text { interval (yrs) }\end{array}$ & $\begin{array}{l}\text { Number of } \\
\text { hips at start }\end{array}$ & $\begin{array}{l}\text { Number withdrawn } \\
\text { during interval }\end{array}$ & $\begin{array}{l}\text { Revision for } \\
\text { any reason }\end{array}$ & $\begin{array}{l}\text { Hips at } \\
\text { risk }\end{array}$ & $\begin{array}{l}\text { Annual failure } \\
\text { rate }(\%)\end{array}$ & $\begin{array}{l}\text { Annual success } \\
\text { rate }(\%)\end{array}$ & $\begin{array}{l}\text { Cumulative } \\
\text { survival rate (\%) }\end{array}$ \\
\hline 0 to 1 & 152 & 0 & 0 & 152 & 0 & 100 & 100 \\
\hline 1 to 2 & 152 & 0 & 0 & 152 & 0 & 100 & 100 \\
\hline 2 to 3 & 152 & 1 & 0 & 151.5 & 0 & 100 & 100 \\
\hline 3 to 4 & 151 & 2 & 0 & 150 & 0 & 100 & 100 \\
\hline 4 to 5 & 149 & 1 & 0 & 148.5 & 0 & 100 & 100 \\
\hline 5 to 6 & 148 & 3 & 0 & 146.5 & 0 & 100 & 100 \\
\hline 6 to 7 & 145 & 6 & 0 & 142 & 0 & 100 & 100 \\
\hline 7 to 8 & 139 & 7 & $1^{*}$ & 135.5 & 0.7 & 99.3 & 99.3 \\
\hline 8 to 9 & 131 & 5 & 0 & 128.5 & 0 & 100 & 99.3 \\
\hline 9 to 10 & 126 & 5 & 0 & 123.5 & 0 & 100 & 99.3 \\
\hline 10 to 11 & 121 & 11 & $2^{\dagger}+2^{\ddagger}$ & 115.5 & 3.5 & 96.5 & 95.8 \\
\hline 11 to 12 & 106 & 12 & 0 & 100 & 0 & 100 & 95.8 \\
\hline 12 to 13 & 94 & 18 & $3^{\ddagger}$ & 85 & 3.5 & 96.5 & 92.4 \\
\hline 13 to 14 & 73 & 9 & $2^{\ddagger}$ & 68.5 & 2.9 & 97.1 & 89.7 \\
\hline 14 to 15 & 62 & 0 & $1^{\ddagger}$ & 62 & 1.6 & 98.4 & 88.3 \\
\hline 15 to 16 & 61 & 46 & $1^{\dagger}+3^{\ddagger}$ & 38 & 10.5 & 89.5 & 79 \\
\hline 16 to 17 & 11 & 9 & 0 & 6.5 & 0 & 100 & 79 \\
\hline 17 to 18 & 2 & 2 & 0 & 1 & 0 & 100 & 79 \\
\hline
\end{tabular}

radiolucency with migration which led to revision as described above.

Radiolucent lines around the component were observed in DeLee and Charnley zone I in three radiographs (2.9\%), in zone II in five $(4.9 \%)$, and in zone III in five $(4.9 \%)$. Sclerosis was seen in zone I in three hips $(2.9 \%)$, in zone II in four $(3.9 \%)$, and in zone III in four $(3.9 \%)$. No lysis was seen around the components.

The linear rate of UHMWPE wear calculated as a simple mean of all available results after a mean follow-up of 14.4 years was $0.07 \mathrm{~mm}$ per year $(0.00$ to 0.30 ).

Femoral component. Subsidence occurred in two femoral components $(1.9 \%)$, and was attributed to undersized stems. One component subsided continuously over the first two years with a total subsidence of $19 \mathrm{~mm}$. After 24 months this component showed no further subsidence. Clinically, the patient was free from pain and had a Harris hip score of 100 at follow-up at 15 years. The second femoral component subsided $8 \mathrm{~mm}$ in the first year after surgery and also stabilised after 24 months. At the last followup, 13.6 years after operation, this patient reported no pain related to the THA.

Radiolucent lines between the stem and the bone were noted in the proximal Gruen zone 1 in 52 hips $(50.5 \%)$ and zone 7 in $26(25.2 \%)$. In zone 1 , lines over $2 \mathrm{~mm}$ wide were seen in $16(15.5 \%)$ and in $11(10.6 \%)$ in zone 7 . In the distal zones 3, 4 and 5, no radiolucent lines were observed. No stem demonstrated a continuous radiolucency reaching the tip of the prosthesis and, therefore, all implants were considered to be stable. Distinct osteolytic lesions were identified in the proximal zones in three radiographs $(2.9 \%)$. Femoral cortical hypertrophy occurred in the distal medial zone 5 in 72 hips $(69.9 \%)$ and in the lateral zone 3 in 33 $(32.0 \%)$. The characteristic radiological findings are given in Figure 2.
Heterotopic ossification arose in 83 hips $(80.6 \%)$ but only $16(15.5 \%)$ were in Brooker stage III and none in stage IV. Calcar rounding with proximal bone resorption was seen in 21 hips $(20.4 \%)$ and was not progressive after two years.

Thickening of the inner cortex around the tip of the stem (zone 4) was observed in 87 hips $(84.5 \%)$. In most cases, the medullary sclerosis occurred on the medial cortex $(55.3 \%)$ and less commonly on the lateral cortex $(23.3 \%)$. Nineteen hips $(18.4 \%)$ showed medial and lateral sclerosis and in five $(4.9 \%)$, a complete pedestal was observed.

Survival. The ten-year cumulative survival with revision for any reason was $95.8 \%$ (Table I). The survivorship with aseptic loosening as a definition of failure was $98.3 \%$ for the acetabular component and $100 \%$ for the femoral component. After 15 years the cumulative overall survivorship decreased to $79.0 \%$ almost entirely because of polyethylene wear.

\section{Discussion}

The Alloclassic total hip system is popular in Europe. We obtained favourable results after a mean follow-up period of 14.4 years. Poor results were mostly related to old age and general health problems, or to periprosthetic disorders such as heterotopic ossification.

The results of all eight SF-36 domains compared with the SF-36 normative values for the gender-matched age group of 65 to 74 years were all within the 25 th percentile. ${ }^{12}$ The median WOMAC physical function, pain and stiffness scores $(2.8,3.9$ and 3.9) for all patients were poorer than the age-matched normative values. In the age group of 65 to 74 years the mean WOMAC functional score was 1.94 (SD 4.3), the mean WOMAC stiffness score 0.34 (SD 6.7) and the mean WOMAC pain score 0.61 (SD 0.61). ${ }^{22}$ Func- 
tion and stiffness of the study group were within one standard deviation of the age-matched normative values. However, the poorer SF-36 and WOMAC scores of the study group could be explained by the influence of various comorbid medical conditions on each of the studied outcomes. $^{23}$

Thigh pain is considered by some authors to be a result of aseptic loosening of the femoral component, related to the design of the implant and the difference in the stiffness between the implant and the bone. ${ }^{24}$ We only observed two cases in our series, both in stable implants. The conical tapered titanium alloy stem has a lower modulus of elasticity than stainless steel or cobalt chrome. This may improve the load transfer from the cementless implant to the cortical bone, minimising micromovement. Burkart et $\mathrm{al}^{25}$ have shown that a straight tapered stem can achieve a better initial stability than an anatomical stem, with a lower incidence of thigh pain.

The radiological data suggest that diaphyseal fixation may provide permanent stability if the design and material allow intimate implant-bone contact. The ten-year survival for the femoral component was $100 \%$ in our study and all stems reached the minimum follow-up of ten years without signs of deterioration or loosening. The first and only revision of the stem occurred after 13.6 years because of loosening created by increased polyethyelene wear.

The Alloclassic stem is designed for a diaphyseal press-fit fixation which leads to proximal stress shielding and diaphyseal cortical hypertrophy. These bony reactions occur within the first years and continue without deterioration in the long term. In our study, radiolucent lines were present in the lateral Gruen zone 1 in $50.5 \%$ and in the medial zone 7 in $25.2 \%$ of cases. All radiolucencies appeared during the first two years after surgery and persisted without further increase in the following years.

Similar changes concerning the proximal stem-bone interface and the distal cortical thickening have been described previously by various authors ${ }^{9,26,27}$ and are typical for uncemented titanium alloy stems using a diaphyseal taper-anchoring concept. Proximal radiolucent lines and distal cortical thickening do not necessarily indicate instability or loosening of the femoral component if they are not progressive after the first two years.

In our study osteolytic lesions were very rare $(2.9 \%)$ and were only found in the proximal zones of the stem. We attribute these findings to the use of a ceramic femoral head instead of a cobalt-chromium head. The advantage of using a ceramic head in combination with a polyethylene liner is a reduction in the wear rate compared with that of a metal head as an articulating partner. ${ }^{28-30}$ Additionally, the method of polyethylene manufacture should be considered. In 1985, Sulzer Orthopedics obtained an essentially homogenous calcium stearate-free polyethylene with substantially improved wear behaviour. ${ }^{31}$ In 1986 , the company commenced sterilising these components using ${ }^{60} \mathrm{Co}-$ gamma irradiation under an inert-gas atmosphere (nitro- gen). ${ }^{32}$ Osteolysis did not seem to be a serious problem for the survival of the implant.

Threaded acetabular components can achieve excellent clinical and radiological results after a follow-up period of more than ten years. With revision of the component for any reason as the end-point, our ten-year survival rate was $97.5 \%$. Similar results were shown in a prospective study by Delaunay and Kapandji. ${ }^{33}$ In our series, the main limiting factor for survival of the acetabular component after implantation for ten years was increased polyethylene wear.

Because of high rates of failure of a variety of threaded acetabular components ${ }^{34-36}$ this form of fixation is not generally considered to be satisfactory. Our data, and those of others, ${ }^{27}$ suggest that screw-thread fixation of acetabular components can be satisfactorily achieved with this particular design. Our data support the continued use of the Alloclassic THA system.

No benefits in any form have been received or will be received from a commercial party related directly or indirectly to the subject of this article

\section{References}

1. Keisu KS, Mathiesen EB, Lindgren JU. The uncemented fully textured Lord hip prosthesis: a 10- to 15-year followup study. Clin Orthop 2001;382:133-42.

2. Schramm M, Keck F, Hohmann D, Pitto RP. Total hip arthroplasty using an uncemented femoral component with taper design: outcome at 10-year follow-up. Arch Orthop Trauma Surg 2000;120:407-12.

3. Mallory TH, Lombardi AV Jr, Leith JR, et al. Minimal 10-year results of a tapered cementless femoral component in total hip arthroplasty. J Arthroplasty 2001;16 (Suppl 1):49-54.

4. Zweymuller K, Semlitsch M. Concept and material properties of a cementless hip prosthesis system with A1203 ceramic ball heads and wrought Ti-6A1-4V stems. Arch Orthop Trauma Surg 1982;100:229-36.

5. Lintner F, Zweymüller KA, Brand G. Histomorphologische befunde bei zementlos implantierten titaniumschäften nach mehriähriger implantation. In: Refior, $\mathrm{HJ}$, ed. Zemeltfreie implantation von hüftgelenksendoprothesen - standortbestimmung und tendenzen. New York: Georg Thieme Verlag Stuttgart, 1987:27 (in German).

6. Zweymuller KA, Lintner FK, Semlitsch MF. Biologic fixation of a press-fit titanium hip joint endoprosthesis. Clin Orthop 1988;235:195-206.

7. Delaunay C, Kapandji Al. Survival analysis of cementless grit-blasted titanium total hip arthroplasties. J Bone Joint Surg [Br] 2001;83-B:408-13.

8. Zenz P, Pospisil C, Fertshak W, Schwagerl W. 10 years of cementless implantation of total hip endoprosthesis using Zweymuller's stem. Z Orthop Ihre Grenzgeb 1995;133:558-61 (in German).

9. Pieringer H, Auersperg V, Griessler W, Bohler N. Long-term results with the cementless Alloclassic brand hip arthroplasty system. J Arthroplasty 2003;18:321-8.

10. Garcia-Cimbrelo E, Cruz-Pardos A, Madero R, Ortega-Andreu M. Total hip arthroplasty with use of the cementless Zweymuller Alloclassic system: a ten to thirteen-year follow-up study. J Bone Joint Surg [Am] 2003;85-A:296-303.

11. Harris WH. Traumatic arthritis of the hip after dislocation and acetabular fractures: treatment by mold arthroplasty: an end-result study using a new method of result evaluation. J Bone Joint Surg [Am] 1969;51-A:737-55.

12. Ware JE Jr, Show KK, Kosinski M, Gande KB. SF-36 Health survey: manual and interpretation guide. Boston: New England Medical Center, The Health Institute, 1994.

13. Bellamy N. Western Ontario and McMaster University Osteoarthritis Index: a user's guide. Vol. 14-16. London, Ontario 1995.

14. DeLee JG, Charnley J. Radiological demarcation of cemented sockets in total hip replacement. Clin Orthop 1976;121:20-32.

15. Gruen TA, McNeice GM, Amstutz HC. "Modes of failure" of cemented stem-type femoral components: a radiographic analysis of loosening. Clin Orthop 1979;141: 17-27.

16. Mulliken BD, Bourne RB, Rorabeck CH, Nayak N. A tapered titanium femoral stem inserted without cement in a total hip arthroplasty: radiographic evaluation and stability. J Bone Joint Surg [Am] 1996;78-A:1214-25.

17. Brooker AF, Bowerman JW, Robinson RA, Riley LH Jr. Ectopic ossification following total hip replacement: incidence and a method of classification. J Bone Joint Surg [Am] 1973;55-A:1629-32. 
18. Dorr LD, Wan Z. Comparative results of a distal modular sleeve, circumferentia coating, and stiffness relief using the Anatomic Porous Replacement II. J Arthroplasty 1996;11:419-28.

19. Cutler SJ, Ederer F. Maximum utilization of the life table method in analyzing survival. J Chronic Dis 1958:8:699-712.

20. Kaplan EL, Meier P. Nonparametric estimation from incomplete observations. J Am Stat Assn 1958;53:457-81.

21. Murray DW, Carr AJ, Bulstrode C. Survival analysis of joint replacements. J Bone Joint Surg [Br] 1993;75-B:697-704.

22. Lieberman JR, Hawker G, Wright JG. Hip function in patients $>55$ years old: population, reference values. J Arthroplasty 2001;16:901-4.

23. McGuigan FX, Hozack WJ, Moriarty L, Eng K, Rothman RH. Predicting qualityof-life outcomes following total joint arthroplasty: limitations of the SF-36 health status questionnaire. J Arthroplasty 1995;10:742-7.

24. Petrou G, Gavras M, Diamantopoulos A, et al. Uncemented total hip replacements and thigh pain. Arch Orthop Trauma Surg 1994;113:322-6.

25. Burkart BC, Bourne RB, Rorabeck CH, Kirk PG. Thigh pain in cementless total hip arthroplasty: a comparison of two systems at 2 years' follow-up. Orthop Clin North Am 1993;24:645-53.

26. Weissinger M, Helmreich C. Long-term results with Zweymuller cement-free Alloclassic stem. Z Orthop Ihre Grenzgeb 2001;139:200-5 (in German).

27. Grubl A, Chiari C, Gruber M, Kaider A, Gottsauner-Wolf F. Cementless total hip arthroplasty with a tapered, rectangular titanium stem and a threaded cup: a minimum ten-year follow-up. J Bone Joint Surg [Am]2002;84-A:425-31.
28. Zichner LP, Willert HG. Comparison of alumina-polyethylene and metal-polyethylene in clinical trials. Clin Orthop 1992;282:86-94.

29. Semlitsch M, Lehmann M, Weber H, Doerre E, Willert HG. New prospects for a prolonged functional life-spain of artificial hip joints by using the material combination polyethylene/aluminium oxide ceramin/metal. J Biomed Mater Res 1977;11: 537-52.

30. Urban JA, Garvin KL, Boese CK, et al. Ceramic-on-polyethylene bearing surfaces in total hip arthroplasty: seventeen to twenty-one-year results. J Bone Joint Surg [Am] 2001;83-A:1688-94.

31. Schmidt MB, Hamilton JV. The effects of calcium stearate on the properties of UHMWPE [abstract]. Procs Orthopedic Research Society, 1996:277.

32. Streicher RM. Investigation on sterilization and modification of high molecular weight polyethylenes by ionizing irradiation. Beta-gamma 11989:34-43.

33. Delaunay CP, Kapandji Al. Survivorship of rough-surfaced threaded acetabular cups: 382 consecutive primary Zweymuller cups followed for $0.2-12$ years. Acta Orthop Scand 1998;69:379-83.

34. Engh CA, Griffin WL, Marx CL. Cementless acetabular components. J Bone Joint Surg [Br] 1990;72-B:53-9.

35. Kubo T, Inoue S, Maeda T, et al. Cementless Lord total hip arthroplasty: cup loosening common after minimum 10-year follow-up of 103 hips. Acta Orthop Scand 2001; 72:585-90.

36. Bruijn JD, Seelen JL, Feenstra RM, Hansen BE, Bernoski FP. Failure of the Mecring screw-ring acetabular component in total hip arthroplasty: a three to sevenyear follow-up study. J Bone Joint Surg [Am] 1995;77-A:760-6. 